\title{
Ultrastructural changes of kidney in diabetic rats
}

\author{
Miko M, Jakubovsky J, Vrabcova M, Varga I \\ Institute of Histology and Embryology, Faculty of Medicine, Comenius University in Bratislava, Slovakia. \\ michal.miko@fmed.uniba.sk
}

\begin{abstract}
OBJECTIVES: To demonstrate histopathological changes in diabetic kidneys of the rat on ultrastructural level with focusing on glomerular cellular environment.

METHODS: Male Wistar rats were administered streptozotocin and after 8 weeks, their kidneys were studied using qualitative transmission electron microscope analysis.

RESULTS: In diabetic kidneys, the presence of irregularly thickened glomerular membrana basalis (GBM), often up to six times as compared to healthy kidney GBM, mainly around peripheral capillary loops, was striking. We also demonstrated lamination and split appearance of GBM, with presence of delicate fibrillar structure, which was absent within normal GBM. Accumulation of mesangial matrix was found only occasionally.

CONCLUSION: Model may be useful to better understand the mechanisms that play role in the progression of DM-induced renal disease and to comprehend the morphological changes, which this process leaves within the tissue. The clear association between ultra-structure and functional markers may not be necessary (Fig. 4, Ref. 27). Text in PDF www.elis.sk. KEY WORDS: diabetic nephropathy, TEM, glomerular basement membrane, mesangium.
\end{abstract}

\section{Introduction}

In developed countries, the occurrence of diseases affecting kidneys is on the rise. This applies not only to renal cell carcinoma, which accounts for approximately $85 \%$ of all kidney cancers (1), but also for chronic metabolic diseases damaging kidneys, most notably for diabetes mellitus (DM). Revolutionary work by Kimmelstiel and Wilson in 1936 (2) was that turning point, which drew attention to the pathological alterations of the kidney in DM and its association with diabetic nephropathy. This pioneer paper, although many its statements stood the test of time till nowadays, is nevertheless eighty years old; hence, we tried to add new insight to this widely discussed issue.

Diabetic nephropathy is multifactorial complication of the underlying disease - DM, whose long-term consequences are manifested as a chronic renal insufficiency. It is characterized by glomerular hypertrophy, basement membrane thickening, disruption of the glomerular permeability barrier, progressive accumulation of glomerular matrix, culminating in glomerulosclerosis, tubulointerstitial fibrosis, and progressive proteinuria and deterioration of renal function (3). Alterations in the extracellular matrix are a prominent feature in diabetic nephropathy.

Animal diabetic models are generally well accepted by scientific community as a tolerable approximation, suitable for research purposes (having in mind their limitations) (4-7). Streptozotocin-

Institute of Histology and Embryology, Faculty of Medicine, Comenius University in Bratislava, Slovakia

Address for correspondence: M. Miko, Institute of Histology and Embryology, Comenius University, Sasinkova 4, SK-81108 Bratislava, Slovakia. Phone: +421.2 .59357547$ induced DM in Wistar rats is often used as a model for studying consequences of DM on kidneys.

All changes mentioned above are well visible under the transmission electron microscope (TEM), thus, we set up an experiment using animal diabetic kidneys for studying morphological correlates of molecular changes, which occur in kidneys, especially in glomerular tuft of capillaries.

\section{Material and Methods}

Tissue

Our animal model worked with streptozotocin-induced DM type I. The material for our study we had obtained from other, previous work of our colleagues (8) - from the kidney of diabetic male Wistar rats. For purposes of this experiment, they were divided randomly into two groups, one serving as a healthy control.

After acclimation (one week), rats were fasted for $6 \mathrm{~h}$ prior the administration of an intraperitoneal injection of streptozotocin (30 mg / kg / day for three consecutive days). DM was confirmed by tail vein blood sampling of glucose concentration. Rats were housed at constant temperature $\left(20 \pm 1.8^{\circ} \mathrm{C}\right)$ and relative humidity $(50 \pm 10 \%)$ in standard polypropylene cages, two per cage, under a $12 \mathrm{~h}$ light/dark. They were fed with commercial rat cube diet and given water ad libitum.

After sacrificing using thiopenthal anaesthesia ( 8 weeks after onset of DM), the tissue from kidneys was harvested and decapsulated, immediately processed for further use.

\section{Electron microscopy histological technique}

For the purposes of electron microscopy, samples, which were $1 \mathrm{~mm}^{3} \mathrm{big}$, were fixated at the room temperature for 3 hours in 


\section{1-165}

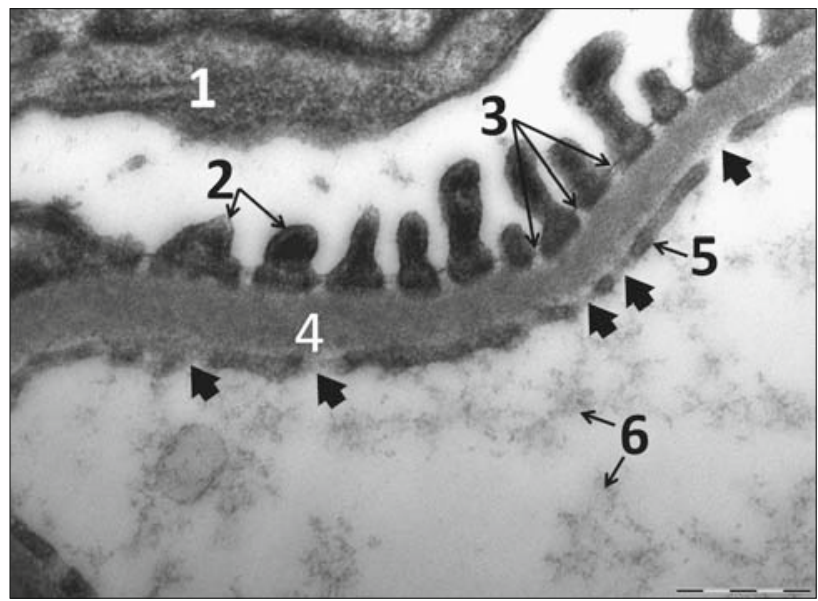

Fig. 1. Electron micrograph of the rat glomerulus, control (healthy) kidney. 1 - body of the podocyte; 2 - numerous pedicles of podocytes abutting the glomerular basement membrane (GBM); 3 - diaphragm between the pedicles of podocytes; 4 - GBM without thickening ; 5 fenestrated endothelia (arrowheads); 6 - precipitated plasma proteins. Lead citrate and uranyl acetate $(\mathrm{Pb}$ Citrate $+\mathrm{UA})$; orig. magn. 28000x.

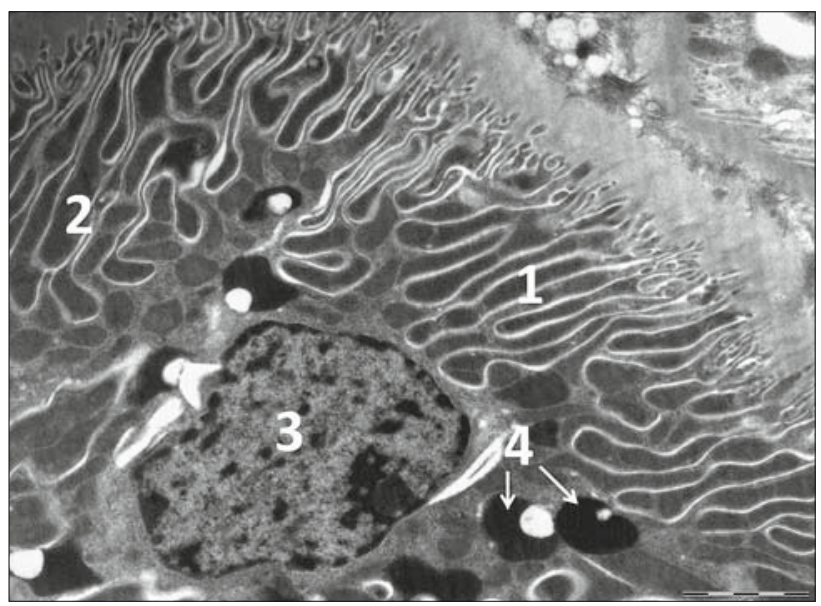

Fig. 2. Electron micrograph of the proximal tubule, control (healthy) kidney. Large euchromatic nucleus (3) with large mosaic nucleolus, 1 - basal infoldings of plasma membrane with large number of mitochondria; 2 -lateral infoldings of plasma membrane of two neighboring epithelial cell; 4 - lysosomes in the cytoplasm. Pb Citrate +UA; orig. magn. $7100 x$.

$2.5 \%$ glutaraldehyde solution in phosphate buffered saline $(\mathrm{pH}$ 7.2). Then, tissue with fixative was rinsed with the cooled phosphate buffer with $10 \%$ sacharose, 3 times for 30 minutes and left sealed for one night in the refrigerator. For postfixation, we used Millonig solution containing 1\% osmium tetroxide ( $\mathrm{pH} 7.2$ ). After dehydration with ascended grades of ethanol, the tissue was transferred to an embedding medium through propylene oxide. The epoxy resin used in experiment was Durcupan (Fluka, Switzerland). Polymerization took place at $60{ }^{\circ} \mathrm{C}$ and lasted 3 days.

Subsequently, specimen was cut with ultramicrotome. The fine slices were contrasted with alcoholic uranyl acetate solution (we tried both methanolic and $98 \%$ ethanolic uranyl acetate solution) and Reynolds solution (9).
We compared specimens from diabetic kidney with those from healthy kidneys. We were looking for a typical ultrastructural morphological correlates of diabetic nephropathy using TEM.

For TEM analysis, we used FEI Morgagni 268D, 100KV with tungsten filament (Czech Republic).

\section{Results}

Using our diabetic model, we have generally demonstrated the changes that occur in streptozotocin-induced DM in kidneys, focusing on glomerulus. In diabetic kidneys, the presence of irregularly thickened glomerular membrana basalis (glomerular basement membrane; GBM), often up to six times as compared to healthy kidney GBM, mainly around peripheral capillary loops, was striking. We also demonstrated lamination and split appearance of GBM, with presence of delicate fibrillar structure, which was absent within normal GBM. Accumulation of mesangial extracellular matrix (ECM) proteins we found only occasionally. Generally, we cannot conclude that we saw typical picture of nodular nor diffuse intercapillary glomerulosclerosis. Normal mesangial matrix in healthy glomerulus was located between capillary lumens, from which it was largely separated by endothelial cells, but sometimes it appeared to be in the direct contact with the bloodstream. The occurrence of Armanni-Ebstein cells (lesions) in the proximal tubule of diabetic kidney, we were not able to confirm with certainty. Our results are summarized in Figure 1.

\section{Conclusion and discussion}

We concentrated on glomerular tuft and to the lesser extent on tubular system of the nephron, because diabetic nephropathy is caused primarily by advanced glomerulopathy as the renal expression of diabetic microangiopathy (10). Podocyte loss may be the crucial contributor to this progressive sclerosis. There is a distinct predilection of segmental sclerosis to occur at the glomerulotubular junction in type 1 diabetic patients, which can lead to disruption of outflow from the glomerulus, resulting in so-called tubular glomeruli (11).

We had not studied Bowman's capsule nor vasculature (vasa afferentia/efferentia), however, it was obvious that important morphologic changes occurred also there (arteriolar hyaline lesions, fibrin-cap or exudative lesions, capsular drop lesions) (12). It is indisputable that the current mainstream research is concentrated on pathomorphology and pathophysiology on the molecular level. But we should be able to visualize and mainly to discern these changes on ultrastructural level, using TEM. That is why we decided to draft this paper.

While studying glomerular filtration barrier, one markedfeature was recorded; rare vacuolization of endothelium in some peripheral loops of glomerular tuft (pictured in figure $3 \mathrm{~g}$ ). Some authors suggested that vacuolization of cytoplasm of podocytes and endothelial cells was associated with focal segmental glomerulosclerosis. Salwa-Zurawska with her team (13) did not confirm this hypothesis, what was consistent with our findings. Vacuolelike endothelial changes within the capillary were related to the 


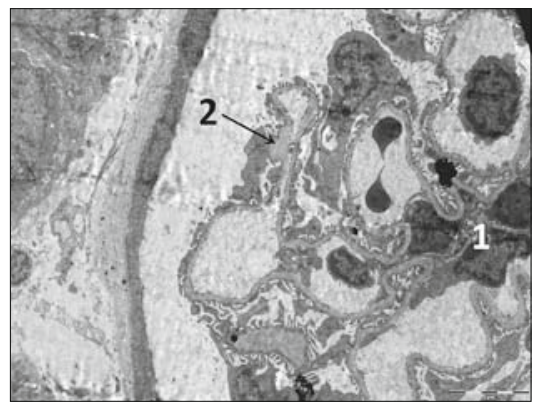

Fig. 3a. Electron micrograph of the rat glomerulus, diabetic kidney (I). Uneven thickness of GBM; 1 - mesangial matrix without evident signs of expansion; 2 - evident focal thickening of GBM. Pb Citrate +UA; orig. magn. 18000x.

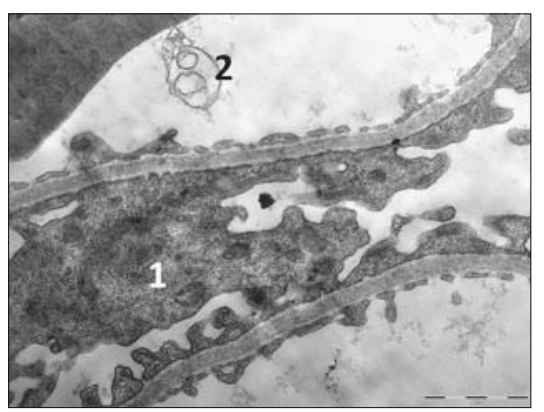

Fig. 3d. Electron micrograph of the rat glomerulus, diabetic kidney (IV). Capillary loop with erythrocyte ghost (2); 1 - body and pedicles of podocytes with noticeable microfilaments and microtubules within its cytoplasm, merging of podocyte pedicles. $\mathrm{Pb} \mathrm{Ci}$ trate $+\mathrm{UA}$; orig. magn. $11000 x$.

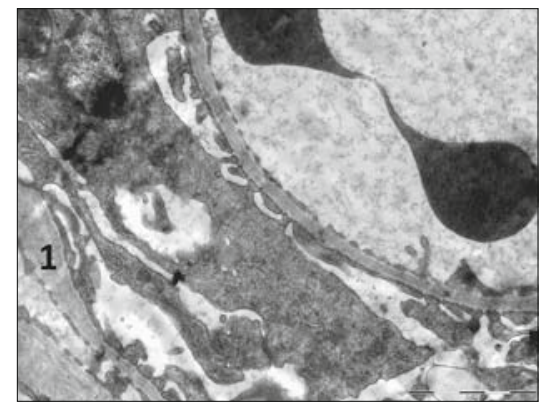

Fig. 3b. Electron micrograph of the rat glomerulus, diabetic kidney (II). Capillary loop with erythrocyte, GBM and podocyte; 1 focal thickening of GBM.Thickeningandloss of podocyte pedicles.Pb Citrate +UA; orig. magn. 18000x.

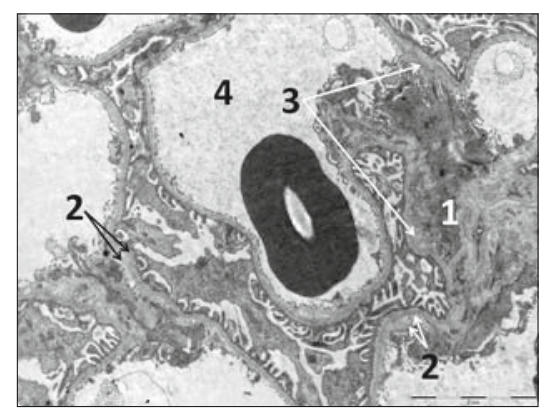

Fig. 3e. Electron micrograph of the rat glomerulus, diabetic kidney (V). 1 - focal expansion of extracelullar mesangial matrix; 2 - splitting of GBM on various spots; 3 - thickening of GBM; lumen of one of the centrally placed loop of capillary with erythrocyte and protein remnants. Pb Citrate $+\mathrm{UA}$; orig. magn. 4400x.

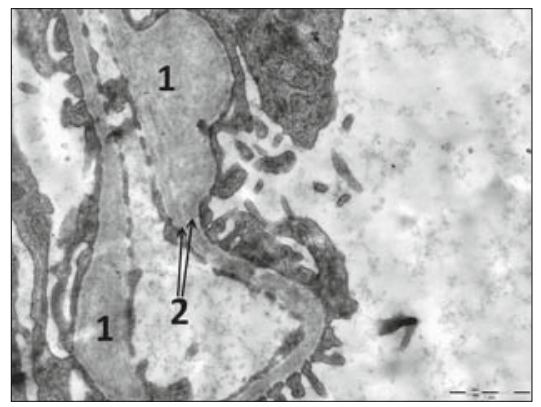

Fig. 3c. Electron micrograph of the rat glomerulus, diabetic kidney (III). Delicate fibrils within the structure of GBM. 1 - enormous thickening of GBM, with splitting (2). Pb Citrate $+U A$; orig. magn. $4400 x$.

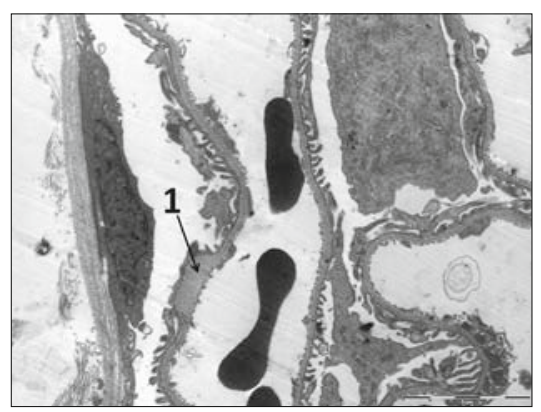

Fig. 3f. Electron micrograph of the rat glomerulus, diabetic kidney (VI). Peripheral capillary loop with erythrocytes and 1 - apparent thickening of GBM.Pb Citrate +UA; orig. magn. 4400x.

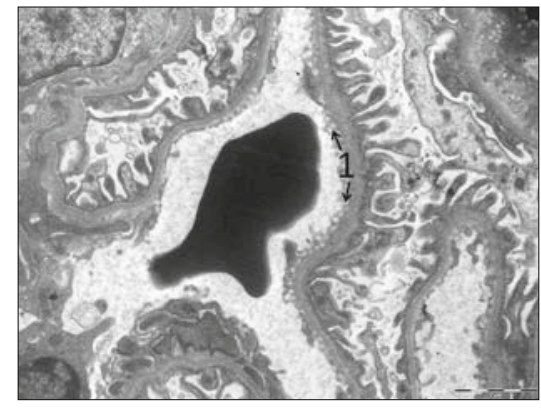

Fig. 3g. Electron micrograph of the rat glomerulus, diabetic kidney (VII). 1 - atypical vacuolization of fenestrated endothelium. Pb Citrate $+\mathrm{UA}$; orig. magn. $7100 x$.

swelling of endothelial cytoplasm or mesangial processes, without direct correlation to development of segmental glomerulosclerosis. We considered, whether this morphological appearance of vacuolization might be the sign of transcytosis and therefore the sign of significant metabolic activity.

Armanni-Ebstein cells are altered epithelial cells of the proximal tubule and the loop of Henle with accumulation of conglomer- ates of glycogen within their cytoplasm. As diabetic patients are treated long term even before the epithelial cells can be changed this way, it is very rare to see this changes in the medical practice. Recently, the Armanni-Ebstein cells were in the center of interest of many researchers, since there is an evidence that they, except of accumulation of glycogen, can store lipids, and they can undergo subnuclear lipidic vacuolization (14). They are one of the few specific morphological correlates of diabetic nephropathy, which does not affect the glomerulus, but tubulointerstitial space instead $(11,15)$.

It should be on the mind: we did not intervene with treatment - we could see the alterations, which are very rare now in patients. Another fact to be reckoned with is that range of other lesions may be present in addition to diabetic nephropathy. The fact, that we were not able to demonstrate some typical changes (accumulation of mesangial matrix, Armanni-Ebstein lesions), at least at the expected extent, might suggest that here are limitations of the informative value of the discussed animal model. But the truth is, that this (or similar) animal model was being extensively used, even with the same time period between the onset of DM and sacrificing (e.g. 16-18). It can be possible that the period 


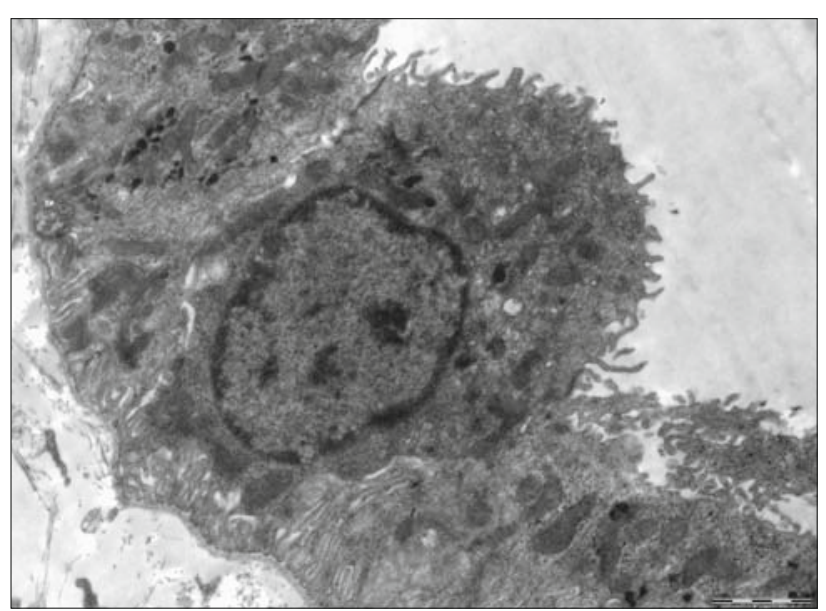

Fig. 4. Electron micrograph of the rat distal tubule, diabetic kidney. Epithelial cell of distal tubule, with large euchromatic nucleus and irregular and poorly developed microvilli and basal infoldings of plasma membrane. Pb Citrate + UA; orig. magn. 11000x.

of several weeks is not a sufficient time for DM to provoke and mainly to develop all the histopathological correlates of diabetic nephropathy in this particular case, although the functional state manly informs about the progression of the disease. On the contrary, the fact that flagrant thickening of the GBM was well documented is in the consonance with other authors who reported this thickening in patients with DM of recent onset (19). Histopathological studies on diabetic microangiopathy have established the thickened vascular basement membrane as one of the first and foremost structural abnormalities (11). The volume of basement membrane located along with peripheral capillary loops increased by nearly 50 percent in the first 4 days of experimental DM (20). Evidence suggests that this fundamental structural lesion develops, at least in part, from an excess accumulation of basement membrane material in the vessel walls (21). When the GBM is thickened, its fibrillary character is accentuated and it often acquires a laminated configuration (22). Farquhar, McDonald and Ireland (23) described dark fibrillar material with a periodicity resembling fibrin in a subendothelial position and contiguous with basement membrane. In our material we did not find any of mentioned structures. Sometimes, in addition to thickening, an extensive wrinkling and corrugation of GBM can be found. This represents ischemic changes in the glomeruli, secondary to the presence of arteriolar disease. Effacement of pedicles can occur with any of these GBM alterations (24).

In past, it was believed that equation was quite simple; the changes in peripheral basement membrane and in mesangial matrix develop in concert and both contribute to the early stage of glomerulopathy in patients with microalbuminuria. But recent data suggest that sometimes, there is no clear association between glomerulosclerosis and functional markers like albuminuria in type 1 and 2 DM. Correlation between albuminuria and mesangial expansion was not significant in some experimental models (25). An accumulation of mesangial extracellular matrix (ECM) proteins, otherwise a typical finding for DM (26), was found only occasionally. And, it can be said, together with Brown et al. (27), that thickening of the GBM in DM does not necessarily coincide with increased urinary albumin excretion as well.

To conclude, our model may be useful to better understand the mechanisms that play role in the progression of DM-induced renal disease and to comprehend the morphological changes, which this process leaves within the tissue.

\section{References}

1. Hodorova I, Solar P, Mihalik J, Vecanova J, Adamkov M, Rybarova S. Investigation of tumour supressor protein p53 in renal cell carcinoma patients. Biomed Pap Med Fac Univ Palacky Olomouc Czech Repub 2014; 158 (1): 44-49.

2. Kimmelstiel P, Wilson C. Benign and Malignant Hypertension and Nephrosclerosis: A Clinical and Pathological Study. Am J Pathol 1936; 12 (1): 45-82.

3. Yung S, Chau MK, Zhang Q, Zhang CZ, Chan TM. Sulodexide decreases albuminuria and regulates matrix protein accumulation in C57BL/6 mice with streptozotocin-induced type I diabetic nephropathy. PLoS One 2013; 8 (1): e54501.

4. Kucharska J, Gvozdjakova A, Stefek M, Sotnikova R, Sumbalova Z. Adaptive changes of antioxidant status in development of experimental diabetes. Bratisl Lek Listy 2001; 102 (11): 515-519.

5. Lee JH, Yang SH, Oh JM, Lee MG. Pharmacokinetics of drugs in rats with diabetes mellitus induced by alloxan or streptozocin: comparison with those in patients with type I diabetes mellitus. J Pharm Pharmacol 2010; 62 (1): 1-23.

6. Sakata N, Yoshimatsu G, Tsuchiya H, Egawa S, Unno M. Animal models of diabetes mellitus for islet transplantation. Exp Diabetes Res 2012; 2012: 256707.

7. Waczulíková I, Cagalinec M, Ulicná O, Slezák P, Ziegelhöffer A. Biophysical investigation on left ventricular myocytes in rats with experimentally induced diabetes. Physiol Res 2010; 59 Suppl 1: S9-17.

8. Kristová V, Lísková S, Sotníková R, Vojtko R, Kurtanský A. Sulodexide improves endothelial dysfunction in streptozotocin-induced diabetes in rats. Physiol Res 2008; 57 (3): 491-494.

9. Reynolds ES. The use of lead citrate at high $\mathrm{pH}$ as an electron-opaque stain in electron microscopy. J Cell Biol 1963; 17: 208-212.

10. Osterby R. Glomerular structural changes in type 1 (insulin-dependent) diabetes mellitus: causes, consequences, and prevention. Diabetologia 1992; 35 (9): 803-812.

11. Najafian B, Alpers CE, Fogo AB. Pathology of human diabetic nephropathy. Contrib Nephrol 2011; 170: 36-47.

12. Holderied A, Romoli S, Eberhard J, et al. Glomerular parietal epithelial cell activation induces collagen secretion and thickening of Bowman's capsule in diabetes. Lab Invest 2015; 95 (3): 273-282.

13. Salwa-Zurawska W, Woźniak A, Biczysko W, Bortkiewicz E, Kaczmarek E, Maciejewski J. Is vacuolization of podocytes and glomerular endothelial cells of prognostic value with respect to FSGS? Pol J Pathol 1998; 49 (3): 165-174.

14. Zhou C, Yool AJ, Nolan J, Byard RW. Armanni-Ebstein lesions: a need for clarification. J Forensic Sci 2013; 58 Suppl 1: S94-98. 
15. Watanabe Y, Hotta N. Tubulointerstitial injury in diabetes mellitus (including Armanni-Ebstein lesion). Ryoikibetsushokogunshirizu 1997; (17 Pt 2): 225-228.

16. Lu WN, Zheng FP, Lai DW, Li H. Xuezhikang reduced renal cell apoptosis in streptozocin-induced diabetic rats through regulation of Bcl-2 family. Chin J Integr Med 2015 Apr 6. [Epub ahead of print]

17. Moon HI. Effect of osajin and pomiferin on antidiabetic effects from normal and streptozotocin-induced diabetic rats. Nat Prod Commun 2014; 9 (12): $1723-1724$.

18. Satyam SM, Bairy LK, Pirasanthan R, Vaishnav RL. Grape seed extract and Zinc containing nutritional food supplement delays onset and progression of Streptozocin-induced diabetic cataract in Wistar rats. J Food Sci Techno. 2015; 52 (5): 2824-2832.

19. Suzuki Y, Churg J, Grishman E, Mautner W, Dachs S. The Mesangium of the Renal Glomerulus: Electron Microscopic Studies of Pathologic Alterations. Am J Pathol 1963; 43 (4): 555-578.

20. Osterby R, Gundersen HJ. Fast accumulation of basement membrane material and the rate of morphological changes in acute experimental diabetic glomerular hypertrophy. Diabetologia 1980; 18 (6): 493-500.
21. Roy S, Sato T. Role of vascular basement membrane components in diabetic microangiopathy. Drug News Perspect 2000; 13 (2): 91-98.

22. Dachs S, CHurg J, Mautner W, Grishman E. Diabetic Nephropathy. Am J Pathol 1964; 44: 155-168.

23. Farquhar A, MacDonald MK, Ireland JT. The role of fibrin deposition in diabetic glomerulosclerosis: a light, electron and immunofluorescence microscopy study. J ClinPathol 1972; 25 (8): 657-667.

24. Tisher CC, Hostetter TH. Diabetic Nephropathy. In: Tisher CC, Brenner BM (Eds). Renal Pathology: with Clinical and Functional Correlations, vol. II. Philadelphia: J.B. Lippincott, 1989: 1309-1334.

25. Abe H. Recent progress in understanding the molecular pathogenesis of diabetic nephropathy. RinshoByori 2011; 59 (2): 179-186.

26. Park JT, Kato M, Lanting $L$ et al. Repression of let-7 by transforming growth factor- $\beta 1$-induced Lin 28 upregulates collagen expression in glomerular mesangial cells under diabetic conditions. Am J Physiol Renal Physiol 2014; 307 (12): F1390-1403.

27. Brown DM, Steffes MW, Thibert P, Azar S, Mauer SM. Glomerular manifestations of diabetes in the BB rat. Metabolism 1983; 32 (7 Suppl 1): $131-135$. 